\title{
Joyería artesanal en oro. Producción más limpia
}

Laura Lucía Landazábal Sanmiguel*

Alejandra Rodríguez Acuña**

Juliana Meneses Santa***

María Camila Restrepo Pedrosa****

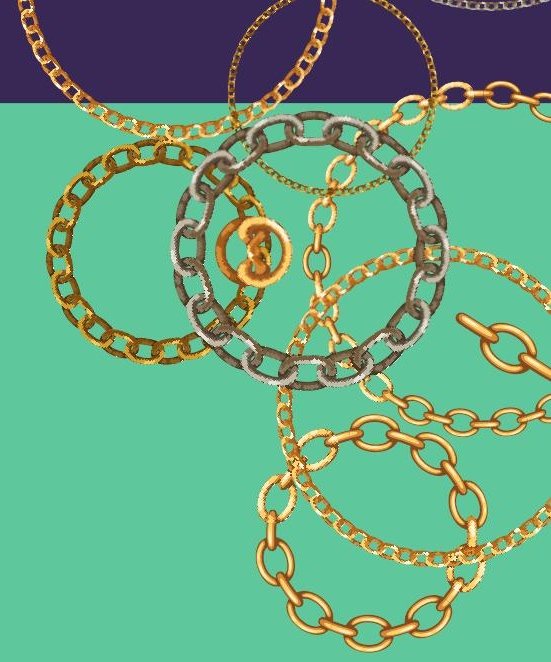

DOI: https://doi.org/10.33571/revinterseccion.v2n4a2

\section{Resumen}

Este artículo tiene como propósito presentar los aspectos y/o impactos de la cadena de producción de la joyería en oro por medio de una indagación y revisión bibliográfica de los procesos productivos en talleres colombianos de joyería artesanal, entendiendo la joyería artesanal como aquel arte elaborado por artesano y orfebres donde su principal materia prima es el oro. El estudio comprende la cadena de producción desde la extracción de los metales hasta la fabricación de los productos, documentando las consecuencias ambientales causadas por la misma cadena en las últimas dos décadas.

Palabras Clave: Joyería; oro; producción; aspectos ambientales; impactos ambientales.

\section{Recibido. Noviembre 05, 2020 \\ Aceptado. Noviembre 16,2020}

*Diseñadora de modas, Magíster en Diseño de Accesorios, actualmente cursando Maestría en Sostenibilidad. Líder del semillero Complementos de Vestuario y Sostenibilidad. Docente facilitador del programa Diseño de Modas en la Institución Universitaria Colegiatura Colombiana. Orcid: https://orcid.org/0000-0003-33530174; e-mail: laura.landazabal@colegiatura.edu.co

**Estudiante de Diseño de Modas de cuarto semestre en la Institución Universitaria Colegiatura Colombiana. Orcid: httos://orcid.org/0000-0002-4818-0560 ; e-mail: alejandra.rodriguez@colegiatura.edu.co

***Estudiante de séptimo semestre de la carrera Diseño Espacios \Escenario, con Doble Programa en Diseño de Modas en la Institución Universitaria Colegiatura Colombiana. Orcid: https://orcid.org/0000-0003-3974-9249 ; e-mail: juliana.meneses@ colegiatura.edu.co

****Estudiante de Diseño de modas de cuarto semestre en la Institución Universitaria Colegiatura Colombiana. Orcid: https://orcid.org/0000-0003-0751-5800 ; e-mail: mariac.restrepo@colegiatura.edu.co 


\section{Handcraffed gold jewelry. Neater production}

Laura Lucía Landazábal Sanmiguel*

Alejandra Rodríguez Acuña**

Juliana Meneses Santa***

María Camila Restrepo Pedrosa****

DOI: https://doi.org/10.33571/revinterseccion.v2n4a2

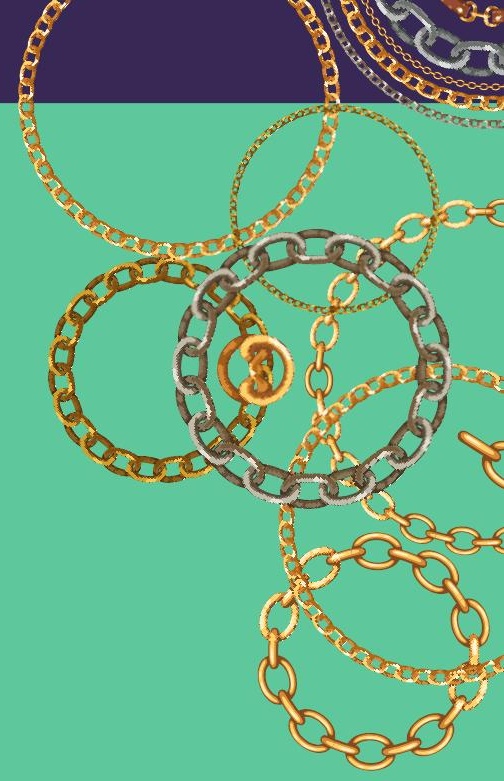

\section{Abstract}

The purpose of this article is to present the aspects and / or impacts of the gold jewelry production through an inquiry and bibliographic review of the production processes in Colombian artisan jewelry workshops, understanding artisanal jewelry as that art made by artisan and goldsmiths where their main raw material is gold. The study covers the production from the extraction of metals to the manufacture of products, documenting the environmental consequences found within the same chain in Colombia in the last two decades.

Keywords: Jewelry; gold; production; environmental aspects; environmental impacts.

Received. November 05, 2020

Accepted. November 16, 2020

*Diseñadora de modas, Magíster en Diseño de Accesorios, actualmente cursando Maestría en Sostenibilidad. Líder del semillero Complementos de Vestuario y Sostenibilidad. Docente facilitador del programa Diseño de Modas en la Institución Universitaria Colegiatura Colombiana. Orcid: https://orcid.org/0000-0003-33530174; e-mail: laura.landazabal@colegiatura.edu.co

**Colegiatura Colombiana student Orcid: https://orcid.org/0000-0002-4818-0560 ; e-mail: alejandra.rodriguez@colegiatura.edu.co

*** Colegiatura Colombiana student. Orcid: https://orcid.org/0000-0003-3974-9249 ; mail: juliana.meneses@colegiatura.edu.co

**** Colegiatura Colombiana student. Orcid: https://orcid.org/0000-0003-0751-5800 ; e-mail: mariac.restrepo@colegiatura.edu.co 


\section{Joias artesanais em ouro.}

\section{Produção mais limpa}

Laura Lucía Landazábal Sanmiguel*

Alejandra Rodríguez Acuña**

Juliana Meneses Santa***

María Camila Restrepo Pedrosa****

DOI: https://doi.org/10.33571/revinterseccion.v2n4a2

\section{Resumo}

O objetivo deste artigo é apresentar os aspectos e/ou impactos da cadeia de produção de jóias de ouro através de uma investigação e revisão bibliográfica dos processos de produção nas oficinas de joalheria artesanal colombianas, entendendo a joalheria artesanal como aquela arte elaborada por artesãos e ourives onde a principal matéria prima é o ouro. O estudo inclui a cadeia de produção desde a extração de metais até a fabricação de produtos, documentando as conseqüências ambientais causadas pela mesma cadeia nas últimas duas décadas.

Palavras Chaves: Joalheria; ouro; produção; aspectos ambientais; impactos ambientais.

Recebido. Novembro 05, 2020

Aceitado. Novembro 16, 2020

*Designer de moda, Mestre em Design de Acessórios, atualmente cursando Mestrado emSustentabilidade. Líder da sementeira de Acessórios de Vestuário e Sustentabilidade. Professor facilitador do programa de Design de Moda do Colombian College College. Orcid: https://orcid.org/0000-0003-3353-0174 ; e-mail: laura.landazabal@ colegiatura. edu.co

** Estudante Colegiatura Colombiana. Orcid: https://orcid.org/0000-0002-4818-0560 ; mail: alejandra.rodriguez@colegiatura.edu.co

*** Estudante Colegiatura Colombiana. Orcid: https://orcid.org/0000-0003-3974-9249; mail: juliana.meneses@colegiatura.edu.co

**** Estudante Colegiatura Colombiana. Orcid: https://orcid.org/0000-0003-0751-5800; e-mail: mariac.restrepo@colegiatura.edu.co 


\section{Introducción}

- ste artículo surge como resultado del - ejercicio de investigación en el semestre 2020-2 del semillero "Complemento del Vestuario y Sostenibilidad", suscrito al programa de Diseño de Modas de la Institución Universitaria Colegiatura Colombiana; con esta indagación y revisión bibliográfica se pretende poner en contexto la joyería en Colombia, sus procesos de fabricación, revisando la relación que existe entre la producción de la joyería en oro en contraste con la situación ambiental y el consumo actual. Cabe anotar que, dentro de este análisis, se identificaron aspectos e impactos ambientales que corresponden a los diferentes procesos que se realizan a partir de las materias primas utilizadas basado en la revisión bibliográfica realizada.

La joyería es un bien que se trabaja en Colombia con una transferencia generacional; cuando se habla de joyería se relaciona enormemente con el sector de la minería, ya que este último abastece una parte de la materia prima, como lo son las piedras o metales preciosos. Es por esto que el artículo busca ahondar la problemática socioambiental que se genera en la explotación de minerales en Colombia, así como explorar la posibilidad de modelos responsables que permitan desarrollar esta actividad y beneficiar a comunidades con menores afectaciones al entorno.

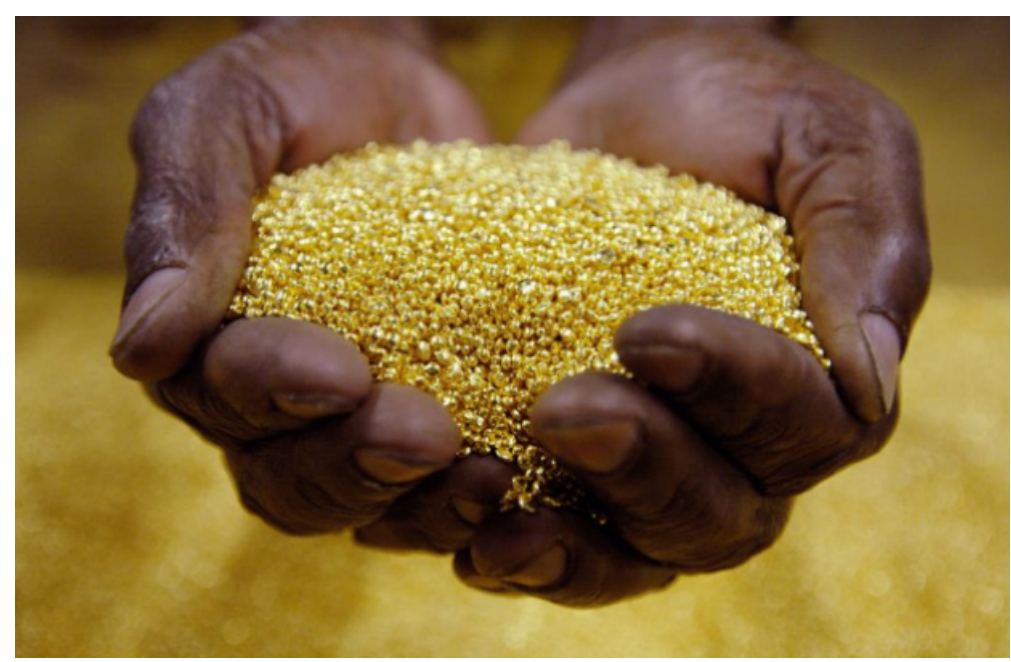

Foto tomada de: http://hablemosdemineria.com/2017/10/25curiosidades-sobre-el-oro/

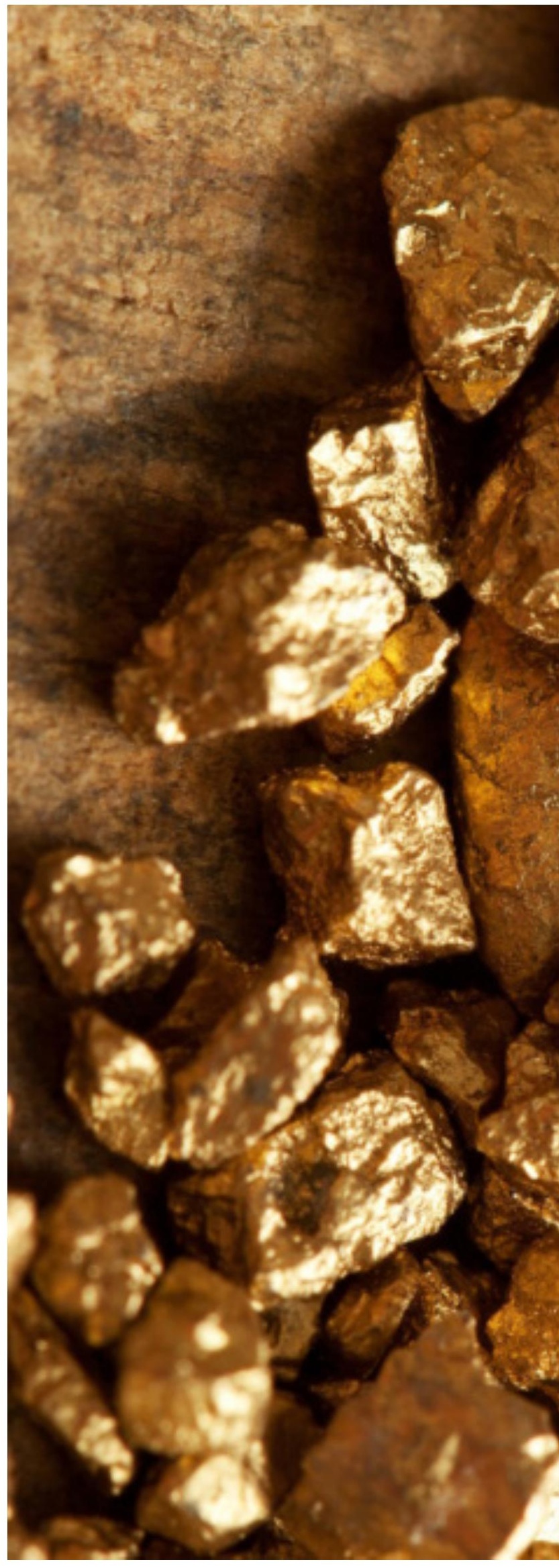


Enlosúltimosañoslasociedadsehaconcientizado más sobre el tema de la sostenibilidad y es por ello, que ahora los consumidores buscan marcas que ayuden a conservar un mundo más limpio, saludable, resiliente y equitativo (Euromonitor international, 2021). Debido a este cambio en el comportamiento del consumidor los talleres de joyería deberían modificar sus prácticas hacia una producción más limpia dentro de la cadena de producción no solo por los beneficios socioambientales sino por los beneficios de comercialización de los productos.

\section{Metodología}

Para este artículo se lleva a cabo una revisión bibliográfica, la cual incluyó, una indagación constante en documentos de las últimas dos décadas como informes sectoriales en joyería, informes de ONG's relacionados a la explotación del oro, informes de entidades gubernamentales referentes a la normativa y evolución del manejo de residuos tóxicos en la extracción del oro, libros y artículos internacionales que proponen prácticas de producción más limpia para la cadena de producción de joyería en oro, además de una visita guiada a Sala Antioquia, ubicada en la Biblioteca Pública Piloto. A través de esto, se indaga acerca del contexto actual en la industria de la joyería en Colombia, la cadena o proceso de producción que se lleva a cabo con las materias primas utilizadas principalmente el oro y se realizó un análisis donde se clasificaron los aspectos e impacto que han dejado los procesos de extracción, moldeado y fabricación de una pieza calada de joyería.

\section{Contexto actual de la industria de joyería en Colombia.}

La industria de la joyería y de la bisutería en Colombia han tenido un gran crecimiento en los últimos años, aumentando a su vez los impactos positivos y negativos. Teniendo en cuenta que tanto la joyería como la bisutería son labores muy dependientes y permeadas de los trabajos manuales, el crecimiento de estas industrias supone el aumento de personal para trabajar estas piezas, es decir aumento de empleo.

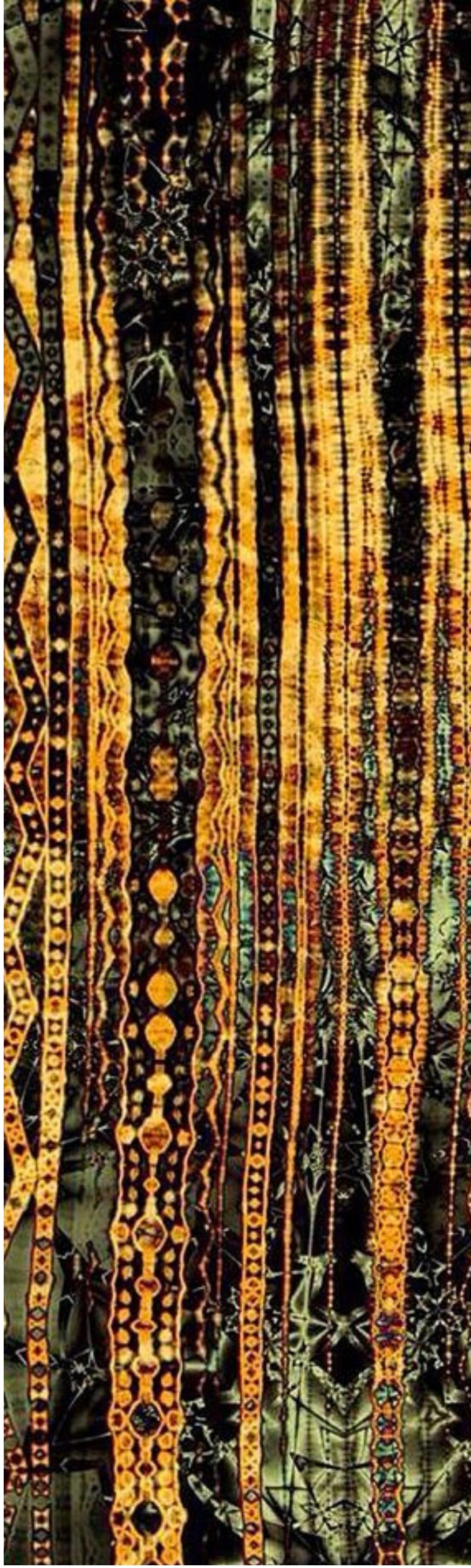


Según el informe de Inexmoda, acerca del sector moda en septiembre de 2020, se encuentra la categoría artículos de joyería con una participación de ventas en el mercado de $22,10 \%$ de las ventas totales de moda después de la categoría de vestuario, superando las ventas de calzado que hasta hace unos años era la segunda categoría de ventas en Colombia después de vestuario.

El panorama para la industria es optimista, según María Claudia Lacouture, entonces presidente de Procolombia, pues el país está en capacidades de responder a la alta demanda internacional, además el producto colombiano resalta debido a su calidad e innovación, especialmente, por la narrativa detrás de los procesos de producción que involucran a poblaciones indígenas, puesto que va de la mano con la tendencia mundial de vincular comunidades con el desarrollo sostenible y de volver las raíces. (Revista Semana, 2015)

Actualmente la joyería en el país está experimentando una evolución hacia la joyería contemporánea, que, aunque ha ido adquiriendo fuerza, es aún casi imperceptible. Según la cámara de comercio de Medellín para Antioquia (2019), la limitación para esta nueva faceta de la joyería se encuentra en dos puntos clave. El primero es la escases de joyeros regidos por las características propias de este tipo de joyería, el segundo, es la limitación en la producción y programas especializados para el diseño de joyas. Adicionalmente muy pocos profesionales del diseño logran encontrar trabajo en esta rama, por otro lado, muy pocas piezas por creador son presentadas al año; complementando esta problemática se encuentra el "antagonismo cultural con la producción en serie" que a su vez afecta la distribución en masa de los productos, y en consiguiente el crecimiento de esta nueva rama. 


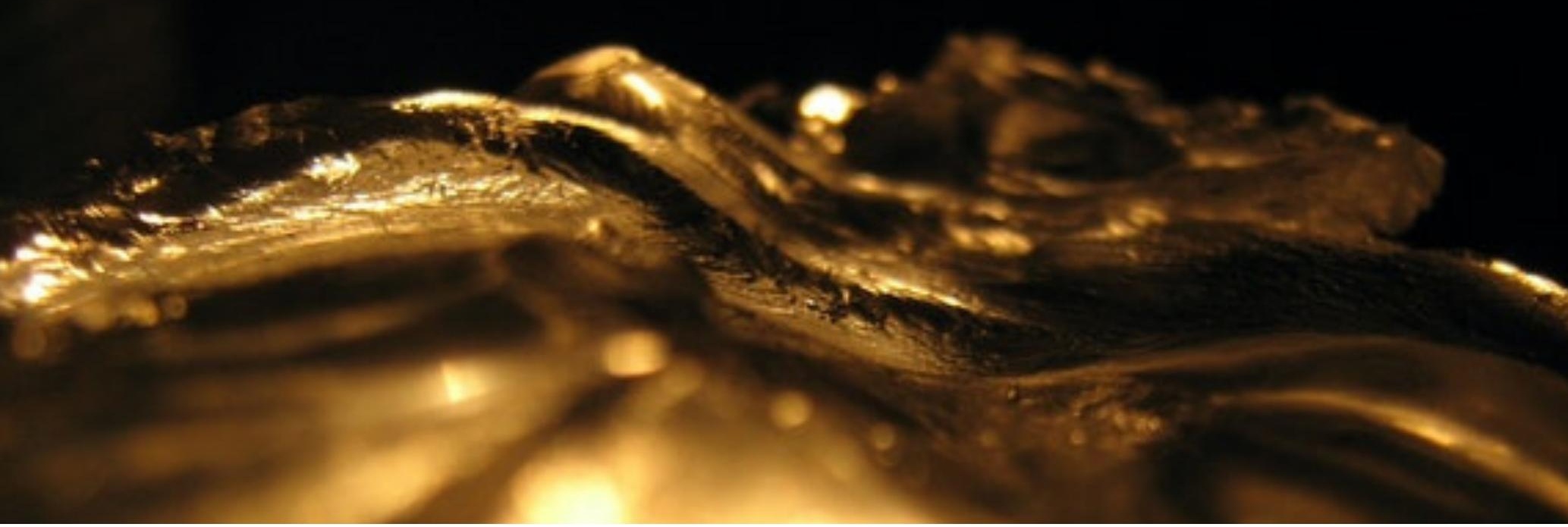

¿En qué se diferencian la joyería contemporánea y la joyería tradicionale La primera proviene de la practica artesanal con origen en los talleres medievales, con influencias del movimiento arts \& crafts anglosajón y los movimientos de joyería radicales de los años 60s. Podría decirse que es un cruce entre el diseño, el arte y la artesanía basándose en la individualidad, artesanía, creatividad y su objeción por la gran reproducción en serie. Con la joyería contemporánea se busca experimentar e investigar con materiales, procesos y conceptos, siendo el valor real del producto el proceso por el cual se llegó a la pieza final, el concepto, el mensaje que transmite y la forma en que lo hace. Mientras que la joyería tradicional debe cumplir con 3 características básicas: tener al menos un metal precioso (oro, plata o platino), al menos una piedra preciosa (rubí, zafiro, esmeralda o diamante) y tener un diseño con acabados precisos e impecables. (cámara de comercio de Medellín, 2019).

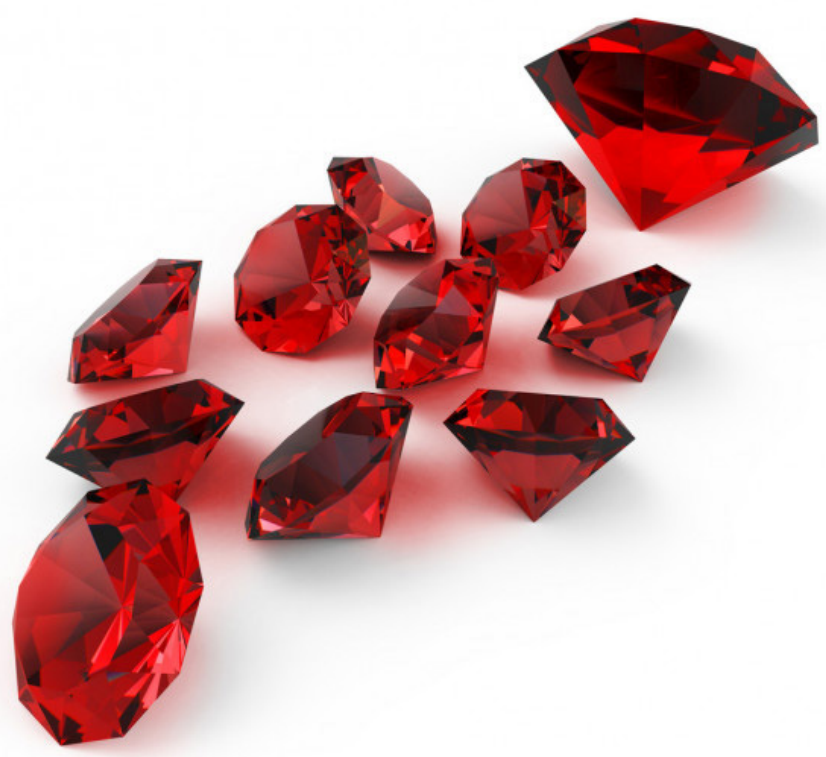

El mercado colombiano es variado pues contiene desde joyería tradicional hasta joyería contemporánea, sin embargo, el protagonismo es aún de la joyería tradicional fácil de encontrar en diversas regiones del país, y con una diversidad de técnicas y diseños que combinan técnicas tradicionales de las zonas con diseños que satisfacen los gustos de los consumidores, logrando así que se mantenga vigente. Cabe resaltar, que, la joyería en oro es la que presenta mayor potencial de ventas en el exterior por el creciente número de compradores internacionales (cámara de comercio de Medellín, 2019). 


\section{Cadena de producción de joyería artesanal}

La cadena de producción de la joyería artesanal es un proceso amplio que incluye diferentes pasos dependiendo del producto final deseado este va desde la extracción de la materia prima hasta el consumidor en un modelo de economía lineal; en este artículo se estudia la cadena de producción desde la minería con la extracción del oro hasta el producto terminado, cabe resaltar que los 11 pasos expuestos solo pretenden ejemplificar el proceso de producción de un diseño especifico de una pieza calada; en la figura 1 se puede ver la representación gráfica de los pasos:

1. Extracción del oro: en este proceso se realiza la extracción del oro por medio de la minería de aluvión o de filón. En Colombia para 2011 el 18\% del oro era extraído de la explotación de filón y el 82\% de aluvión. (UNODC, 2018)

2. Refinación: en este proceso se limpian las impurezas del oro por medio de diferentes métodos (Alguacil, 1995), el quimico usado principalmente para limpiar el oro es el acido nitrico. (Artesanías de Colombia, 2012)

3. Diseño: es el proceso en el cual se crea la propuesta del producto a realizar para comunicar una idea (Wicks, 1996) por medio de una ilustración manual o una ilustración digital

4. Fundición: en este proceso se crean las aleaciones en los metales donde 24 quilates es oro puro, 18 kilates tiene un porcentaje de oro puro aproximado del $75 \%$, para saber qué porcentaje se le debe adicionar de los metales adicionales se multiplica el quilate por el peso del material y se divide por la cantidad de quilates que se quiere obtener, el tipo de material adicional que se une con el oro incide en el color del mismo, ejemplo si se usa cobre, el oro queda rojizo. (Artesanías de Colombia, 2012) para realizar este proceso se usa un soplete con oxígeno y propano para que los metales lleguen al punto de fusión necesario. (Artesanías de Colombia ,2013)

5. Laminado: por medio de una máquina laminadora manual se reduce el grosor de la pieza para poder cortarla y dar forma inicial al diseño, en este paso se debe recocer el material para mejorar la maleabilidad (Artesanías de Colombia, 2012)

6. Recocido: en este proceso se calienta el material por medio de un soplete con gas butano o propano a una temperatura específica (Wicks, 1996), para que el material recupere su maleabilidad y ductilidad. (Artesanías de Colombia, 2012)

7. Corte y calado: en este proceso se transfiere el diseño deseado a la pieza laminada para continuar con el corte y extraer las piezas internas de una lámina por medio de una segueta (Artesanías de Colombia ,2013).

8. Decapado o soluciones limpiadoras: proceso en el cual se eliminan las superficies oxidadas y resto de metal después de la soldadura, este es un baño acido que se puede hacer con alumbre, ácido sulfúrico (Wicks, 1996) o ácido nítrico para conseguir el blanqueado de las piezas.

9. Limado y lijado: este proceso se realiza de manera manual por medio de una lija o lima, en el cual por medio de movimientos continuos en la misma dirección se pulen las diferentes caras de la pieza (Artesanías de Colombia, 2013). 
10. Pulido: en este proceso por medio de una máquina pulidora se da brillo a la pieza usando distintas felpas y pastas para resaltar el brillo natural de los metales, algunos talleres usan tómbolas para este proceso. (Artesanías de Colombia ,2013)

11. Producto final: se obtiene la pieza de joyería lista para su comercialización.

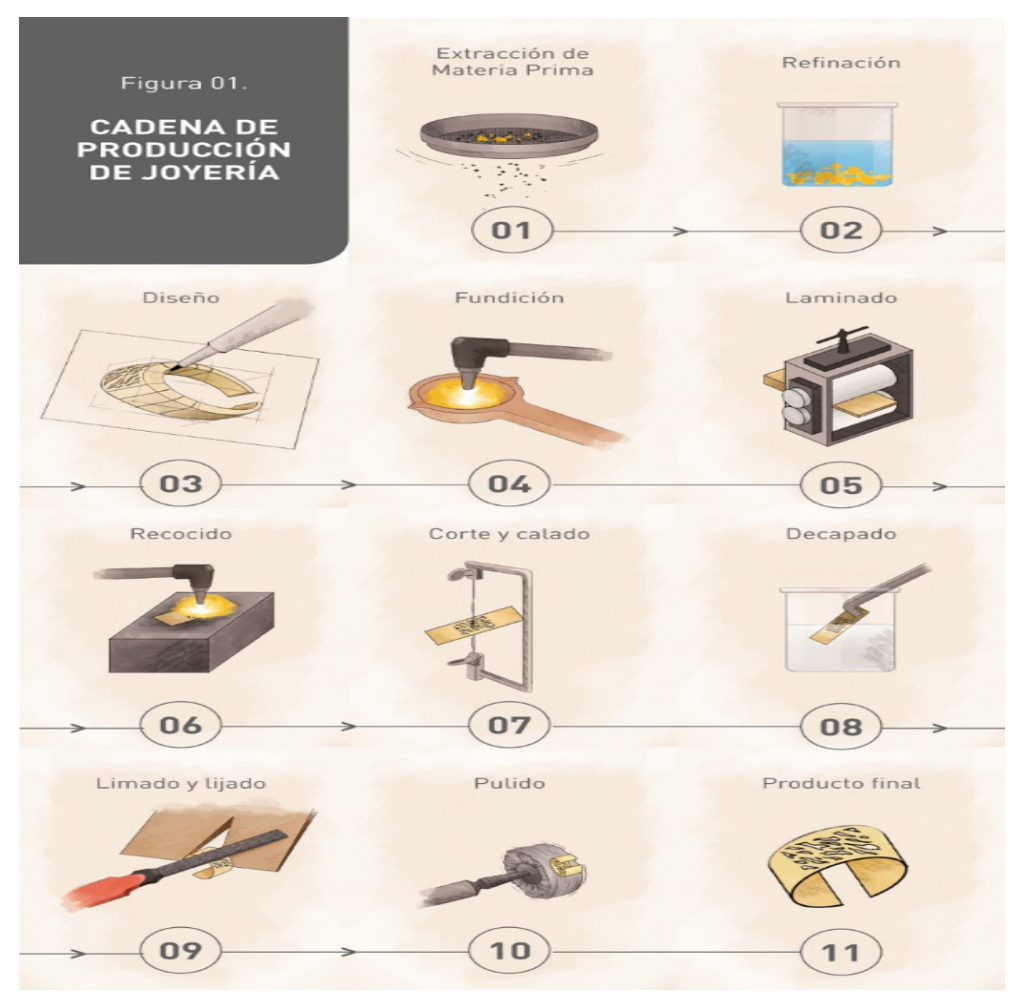

Figura 1. Elaborada por el estudiante Sebastián Gutiérrez del semillero de investigación Caja de Herramientas, suscrito al programa de Diseño Gráfico de la Institución Universitaria Colegiatura Colombiana

\section{Aspectos e impactos ambientales en la cadena de producción de joyería en oro}

Con el fin de ejemplificar de manera clara la cadena de producción ysus consecuencias se realizó una tabla generando la división entre aspectos e impactos ambientales según la norma técnica NTC 1400 I ICONTEC (2004) donde los aspectos se definen como "elemento de las actividades, productos o servicios de una organización que puede interactuar con el ambiente" y los impactos como "Cualquier cambio en el medio ambiente, ya sea adverso o beneficioso, como resultado total o parcial de los aspectos ambientales"; según estas definiciones la figura 2 muestra los resultados de la revisión bibliográfica realizada; es de resaltar que existen estudios importantes en las primeras etapas de la producción que muestran los impactos, pero en las siguientes etapas del procesos se evidencio una falta de investigaciones hacia los impactos ambientales. 


\begin{tabular}{|c|c|c|}
\hline \multicolumn{3}{|c|}{ Figura 02.} \\
\hline ACCIONES & $\begin{array}{l}\text { ASPECTOS } \\
\text { AMBIENTALES }\end{array}$ & $\begin{array}{l}\text { IMPACTOS } \\
\text { AMBIENTALES }\end{array}$ \\
\hline \multirow{3}{*}{$\begin{array}{l}\text { Extracción } \\
\text { del oro }\end{array}$} & Emisiones de $\mathrm{CO}_{2}$ & $\begin{array}{l}\text { No se encontró } \\
\text { información en la } \\
\text { revisión bibliográfica }\end{array}$ \\
\hline & $\begin{array}{l}\text { Vertimientos } \\
\text { de mercurio }\end{array}$ & $\begin{array}{l}\text { Afectaciones a la } \\
\text { salud humana }\end{array}$ \\
\hline & $\begin{array}{l}\text { Tala de } \\
\text { árboles }\end{array}$ & Deforestación \\
\hline Refinación & $\begin{array}{l}\text { Vertimientos de } \\
\text { ácido nítrico }\end{array}$ & $\begin{array}{l}\text { Afectaciones a la } \\
\text { salud humana }\end{array}$ \\
\hline \multirow{2}{*}{ Fundición } & Radiación infrarroja & Riesgo de lesiones \\
\hline & $\begin{array}{l}\text { Emisiones de } \\
\text { material particulado }\end{array}$ & $\begin{array}{l}\text { No se encontró } \\
\text { información en la } \\
\text { revisión bibliogrática }\end{array}$ \\
\hline Recocido & Emisiones de $\mathrm{CO}_{2}$ & $\begin{array}{l}\text { No se encontró } \\
\text { información en la } \\
\text { revisión bibliográfica }\end{array}$ \\
\hline Corte y calado & $\begin{array}{c}\text { Material particulado } \\
\text { de metal pesado } \\
\text { [oro] }\end{array}$ & $\begin{array}{l}\text { No se encontró } \\
\text { información en la } \\
\text { revisión bibliográfica }\end{array}$ \\
\hline Decapado & $\begin{array}{l}\text { Vertimientos de } \\
\text { ácido nítrico }\end{array}$ & $\begin{array}{l}\text { No se encontró } \\
\text { información en la } \\
\text { revisión bibliográfica }\end{array}$ \\
\hline Limado y lijado & $\begin{array}{c}\text { Material particulado } \\
\text { de metal pesado } \\
\text { [oro] }\end{array}$ & $\begin{array}{l}\text { No se encontró } \\
\text { información en la } \\
\text { revisión bibliográfica }\end{array}$ \\
\hline Pulido & $\begin{array}{l}\text { Material particulado } \\
\text { de metal pesado } \\
\text { [orol y ceras usadas }\end{array}$ & $\begin{array}{l}\text { No se encontró } \\
\text { información en la } \\
\text { revisión bibliográfica }\end{array}$ \\
\hline
\end{tabular}

Figura. 2 cuadro elaborado por las autoras basado en los resultados de la indagación y en la norma técnica NTC 14001 instituto colombiano de normas técnicas y certificación. (2004). Sistemas de gestión ambiental. Requisitos con orientación para su uso. NTC 14001. Bogotá, Colombia. ICONTEC.

El oro es un bien de consumo que tiene un alto valor económico, en el último año los altos precios del oro han disminuido la demanda de este mineral para joyería en un $39 \%$ para el primer cuatrimestre de 2020 comparado con las compras al primer cuatrimestre del 2019, sin embargo la demanda específica para joyería sigue siendo la más alta comparada con las otras categorías como tecnología o compra por los bancos centrales con una demanda total mundial de 325.8 toneladas para el primer cuatrimestre del 2020 (world gold council, 2020). 
Los principales departamentos productores de oro en Colombia son: Antioquia con el $47 \%$, Choco con el $21 \%$, Bolívar con el $10 \%$ y Nariño, Cauca y Caldas con un 6\% cada uno; según un censo realizado en 2011 por la Dirección de Formalización del Ministerio de Minas y Energía (MME) se reportaron 102.742 mineros vinculados a trabajos de explotación minera de las 14.357 UPMs censadas, de este número solo el $63 \%$ contaba con un título minero que legaliza la actividad frente a las autoridades nacionales; esto se evidenció en departamentos productores de oro como Antioquia con un $80 \%$ y Choco con un 99\% de informalidad (Betancur, 2019).

La MPE (minería de pequeña escala) o de subsistencia les permite a los productores tener autonomía económica en regiones donde los niveles de pobreza son altos. En 2015 la Gobernación de Antioquia busco formalizar 800 unidades, este proceso lo iniciaron 150 unidades, pero ninguna pudo legalizar la actividad (Verdad Abierta, 2015). En los últimos años se han entregado más títulos mineros a las multinacionales mientras que la MPE de oro se desarrolla con limitaciones para su formalización y con las últimas medidas tomadas por el gobierno que confunden la MPE del oro con una minería criminal (Pantoja, F. \& Pantoja, S., 2019). Muchos mineros han intentado legalizar su actividad, pero según un estudio realizado por la defensoría del pueblo en el 2010 , el $86 \%$ de las solicitudes para la formalización fueron negadas (Betancur, 2019).

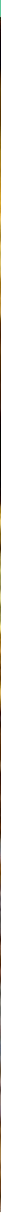


Adicional a esta problemática se le suma que "la tendencia al alza de los precios del oro en el mercado internacional también atrajo a los actores armados. Tanto guerrillas como paramilitares han buscado controlar de manera directa o indirecta estos recursos para financiar la guerra. Así, los mineros ancestrales, pequeños y medianos quedaron atrapados entre multinacionales y actores armados y sometidos, además, a una política estatal de formalización minera que los criminaliza y los expulsa del territorio" (Betancur, 2019, p. 23). Es por esto que se precisan más acciones por parte de las entidades gubernamentales que permitan la protección de los derechos humanos de los MPE o de mineros artesanales.

La explotación ilícita del oro, se define como mineros que no tienen título para legalizar su actividad frente a las autoridades competentes, este es un fenómeno que tiene una movilidad geográfica amplia debido al potencial aurífero que existe en el país (UNODC, 2018). Choco es el departamento que más presenta evidencias de explotación de oro de aluvión con uso de maquinaria en tierra (EVOA) pero Antioquía es el que más reporta producción de oro. Teniendo esto en cuenta se identifica que la explotación de minerales es una de las principales causas directas de la deforestación en el país, en el periodo de 2018-2019 el país perdió 6.669 hectáreas en cobertura vegetal de alto valor ambiental debido a las actividades mineras (UNODC, 2020). Adicional a esto la extracción de 1 gramos de oro produce $20 \mathrm{~kg}$ de emisiones de CO2, usa 2500 litros de agua y genera 2500 kilogramos de desperdicio (Fettolini, 2018)

Dentro del territorio antioqueño ha sido prospera la extracción masiva del oro; sin embargo y, aunque la joyería actualmente se ha convertido en un bien que, siendo considerado como lujo, es accesible a diferentes públicos, el mal manejo de la materia prima y los insumos que se utilizan para la transformación y creación de las piezas ha tenido efectos adversos que desencadena problemas ambientales. En referencia al departamento de Antioquia, y de acuerdo con una investigación de mercados realizada por parte de Intermarketing Consultores, se han visto afectaciones en la capa vegetal y en aquellos márgenes de los causes hídricos, esto debido a la contaminación y sedimentación que se produce gracias al uso de sustancias toxicas como el mercurio (Rubio, 2003). El mercurio (Hg) utilizado como mecanismo de extracción de oro es uno de los principales metales pesados contaminantes de los sistemas acuáticos. Dada su alta capacidad

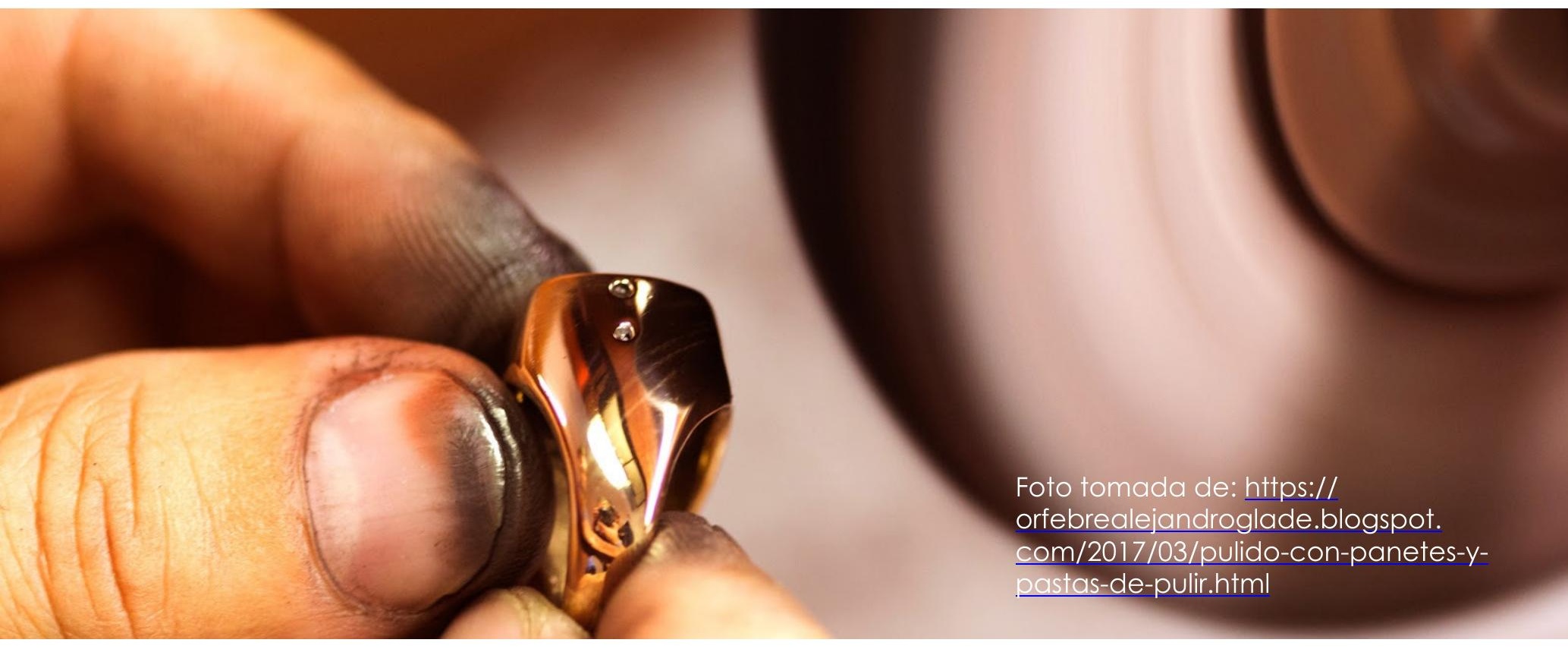


de bioacumulación y biomagnificación en forma de metil-mercurio $(\mathrm{MeHg}+)$, compuesto iónico sumamente tóxico, el mercurio tiene un alto impacto en la biota acuática (Clarkson \& Magos, 2006).

El uso de mercurio está prohibido en la Ley 1658 de 2013, con la cual el Gobierno Nacional decidió hacer una transición de la eliminación del elemento en la minería del oro en el transcurso de 5 años del 2013 al 2018 (Ministerio del medio ambiente, 2018). Adicional a esto se puso en marcha un plan sectorial para la eliminación del uso de mercurio para la pequeña minería y minería de subsistencia del 2016 al 2019, pero a pesar de los esfuerzos según el informe de la contraloría general de la nación solo han avanzado en la eliminación del elemento en un 46.72\%; dentro de los impedimentos para cumplir el objetivo está la falta de subsidios económicos para los mineros artesanales por medio de los cuales podrían tecnificar el proceso para la compra de tecnología que no necesita el uso de mercurio para la obtención del material puro (Contraloría general de la nación, 28 de octubre 2020).

Se infiere de lo anterior, que los impactos ambientales ocasionados por la minería enColombia, a pesardelaumento enlareglamentaciónque havenidoprogresivamente aplicándose en el país, constituyen un tema de preocupación bastante álgido para las organizaciones del estado y no gubernamentales, que tienen en su haber, el cuidado de la multiplicidad de ecosistemas con que se dispone en el país. Por lo tanto, debemos partir de la sensibilización para crear conciencia en las personas que se encargan de extraer estos elementos mineros, recuperando y restableciendo el suelo y la vegetación del área perturbada, añadiendo otros materiales para neutralizar la acidez, los altos niveles de metal en los suelos, teniendo en cuenta que dichas medidas (además de las que se encuentran reglamentadas en los protocolos mineros), se deben de adoptar antes durante y después de la extracción de dichos metales.

Existen alternativas menos perjudiciales para el ambiente como lo son el uso del oro reciclado este mineral se puede reciclar muchas veces sin perder sus propiedades, esta práctica no es nueva se usa desde hace muchos años principalmente por el alto costo del material, sin embargo, cuando se realiza este proceso no se puede garantizar al $100 \%$ que son recicladas ya que muchas veces son mezclados con oro recién extraído, por esto se deben buscar empresas que certifiquen el origen de la materia prima; otra alternativa puede ser el uso del oro con certificación fairmined, este es un sello de aseguramiento que certifica oro de empresas mineras artesanales y de pequeña escala (MAPE), los cuales tienen trazabilidad de origen y mitigaciones de impactos ambientales importantes para la extracción de la materia prima, este es una iniciativa creada por la alianza de minería responsable una ONG con sede en Colombia que es reconocida mundialmente por su trabajo con minería artesanal y de pequeña escala (Fettolini, 2018). Pero más mineros no optan por certificar su oro fairmined debido a que es necesario tener el titulo minero para poder iniciar el proceso de certificación y como se mencionó anteriormente ese continúa siendo un problema para los productores artesanales.

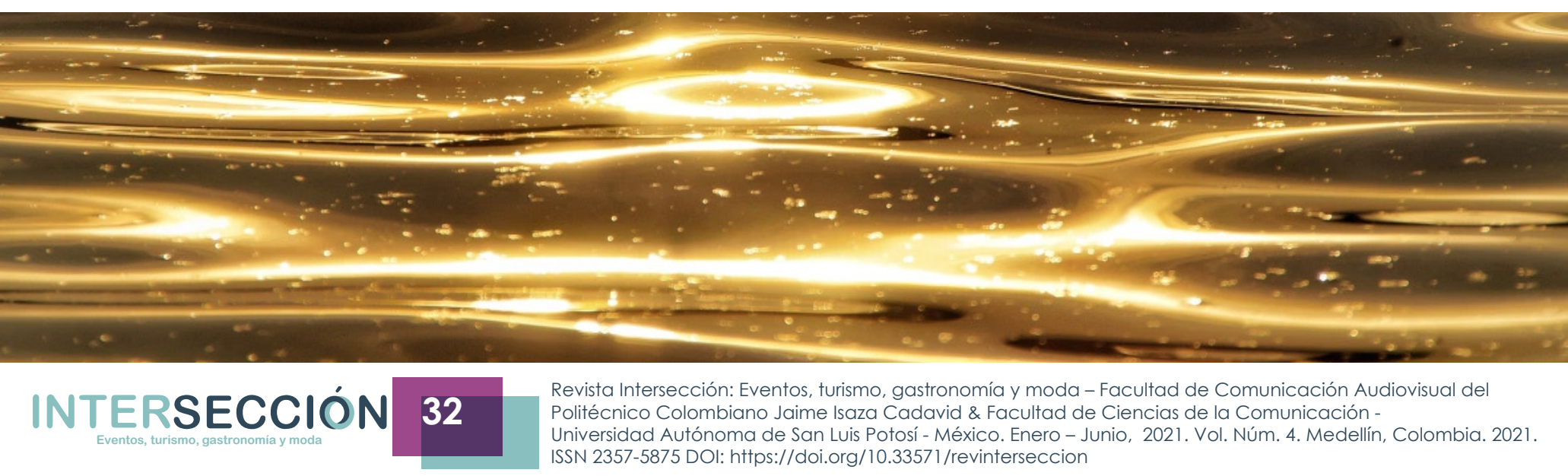


Contrario a lo que podría denominarse una creencia popular, el proceso de extracción de minerales no es único factor involucrado en la producción de joyería que genera residuos que afectan a los trabajadores involucrados en la producción, adicionalmente afectan a diferentes especies de fauna y flora que habitan cerca de minas y talleres de joyería. Particularmente en el proceso de refinación del oro al hacer uso de ácido nítrico (reactivo capaz de disolver los aleantes del oro y del platino), el factor humano corre riesgos al manejar dicho acido, pues al ser toxico y corrosivo, su uso continuo o erróneo deteriora las mucosas, mancha la piel de amarillo y puede ocasionar graves quemaduras cutáneas (Ruiz, Carmona, Bolívar y López, 2017).

En cuanto a la fundición, se presentan riesgos de lesiones por exposición al calor, así como radiación infrarroja de hornos y del metal en fusión (OIT, 2001, como se citó en Ruiz et al, 2017). En cuanto al factor medio ambiental, esta fase se relaciona con emisiones al aire de material particulado (dióxido de azufre, óxidos de nitrógeno, carbonoioxinas y furanos, compuestos orgánicos volátiles, monóxido de carbono, etc..) y altos niveles de contaminación auditiva.

Continuando la cadena de producción el proceso de decapado permite limpiar las piezas del oxido después de los procesos de recocido, para este se usa generalmente 8 partes de agua por una de ácido nítrico, el mismo usado en la refinación, es decir que es un tóxico que no se puede desechar a los afluentes y que pueden afectaciones a la salud humana. Existen alternativas para el decapado como el uso de una solución de agua y vinagre que tienen el mismo efecto de blanqueo en el oro después del recocido, siendo esta la opción más recomendable para disminuir las emisiones tóxicas en el proceso (Fettolini, 2018).

La etapa de pulido y brillo es también contaminante, pues de estos procesos se desprenden pequeñas partículas de metal y abrasivos, que, en sumatoria con el polvo de sílice, vapores y ácidos presentes a lo largo de la cadena de producción, representan un factor altamente nocivo para la salud humana. (Muñoz, L y Beltrán, $M, 2018)$.

\section{Conclusiones}

En los procesos de producción analizados se evidencia el uso de sustancias toxicas, como el mercurio implementado principalmente en la extracción del oro, siendo este el método más empleado para separar y extraer este mineral de las piedras y otros materiales; la prohibición del uso de esta sustancia se encuentra en la ley 1658 del 2013 la cual entró en vigencia el 2018, pero se evidencia una falta de avance en la eliminación de la misma según la contraloría general de la nación (2020); existen alternativas al uso del mercurio, pero por falta de conocimiento o tecnología los MPE siguen usando en más de un $50 \%$ esta sustancia, es por esto que se sugiere que las entidades gubernamentales deberían capacitar a los productores de manera constante en una producción más limpia del oro y realizar auditorías de los procesos al igual que facilitar medios económicos para la compra de tecnología que facilite la obtención del mineral sin necesidad de sustancias toxicas.

Es importante tener en cuenta que los talleres artesanales de joyería controlan el proceso desde la fundición hasta el producto final en su gran mayoría es por esto que existen un potencial para sensibilizar a los diferentes talleres en las alternativas menos perjudiciales en los aspectos socioambientales donde se puede tener un control sobre los vertimientos y usos de sustancias tóxicas para minimizar los impactos sobre los artesanos y el medio ambiente. 


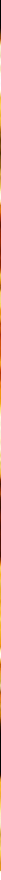

En la actualidad existen alternativas menos perjudiciales para el medio ambiente en la obtención de la materia prima como lo es el uso de oro reciclado, este elemento si mantiene su pureza, puede ser reciclado en un ciclo constante, esto garantiza que no se exploten los recursos naturales, pero esta solución aún presenta problemas de trazabilidad del origen de los recursos, en general la trazabilidad del oro solo se puede garantizar con el sello fairmined, esta opción garantiza el pago justo a los mineros al igual que un manejo responsable de las sustancia tóxicas de la misma actividad garantizando la mitigación de impactos negativos.

Finalmente, dentro de la revisión se encontraron muchos informes, libros y artículos referentes a los primeros dos pasos expuestos, pero al continuar la indagación en los siguientes pasos se evidenció una falta de material técnico frente a los impactos medio ambientales de la cadena de producción, por esto se incentiva a la investigación del ciclo de vida completo de una pieza de joyería artesanal para entender todas las consecuencias reales que rodean este oficio y que se puedan realizar estrategias para eliminar sustancias tóxicas en el proceso.

\section{Bibliografía}

Alguacil, F.J (1995). El refino del oro. Revista de metalurgia, 31 (3), 182-191

Alianza Mundial de Derecho Ambiental (2010). Guía para evaluar ElAs de proyectos mineros. Oregon: Alianza Mundial de Derecho Ambiental (ELAW). Recuperado de https://www.elaw.org/files/mining-eia-guidebook/Guia\%20\%20para\%20Evaluar\%20 EIAs\%20de\%20Proyectos\%20Mineros.pdf

Artesanías de Colombia (2012) Referencia nacional de joyería capitulo municipio orfebre de Mompox filigrana en oro y plata. Recuperado de: https://repositorio. artesaniasdecolombia.com.co/bitstream/001/2818/1/INST-D\%202012.\%20140.pdf

Artesanías de Colombia. (2013) Referencial nacional de joyería capítulo joyería Medellín departamento de Antioquia. Recuperado de: https://repositorio. artesaniasdecolombia.com.co/handle/001/2812

Betancur, M.S. (2019) MINERÍA DEL ORO, TERRITORIO Y CONFLICTO 


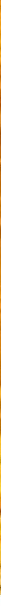

Cámara de comercio de Medellín para Antioquia (2019). Cadena de Joyería en Antioquia. Medellín, Colombia. Cámara de comercio de Medellín para Antioquia. Recuperado de: https://www.camaramedellin.com.co/Portals/0/Biblioteca/ Estudios-economicos/cadenas-productivas-regionales/3\%20 Joyeria_Oc†19. pdf? ver=2019-03-01-090033-067

Contraloría general de la nación (28 de octubre, 2020). Comunicado de prensa no. 153 concluye estudio de la Contraloría: Por debajo del 50\% avanza plan para eliminar uso del mercurio en actividades de beneficio de oro.

Fairmined (2020). Fairmined es oro del cual cuesta estar orgulloso. Recuperado de: https://fairmined.org/es/que-es-fairmined/

Fettolini, J.S (2018) Sustainable jewellery: principles and processes for creating an ethical brand. Barcelona, España. Promopress https://co.boell.org/es/2019/12/09/ mineria-del-oro-territorio-y-conflicto-en-colombia-retos-y-recomendaciones-para-la Inexmoda (2020). Observatorio de moda septiembre 2020. Recuperado de: http://www.saladeprensainexmoda.com/wp-content/uploads/2020/1 1/InformeObservatorio-Sistema-Moda-Septiembre-2020.pdf

Instituto Colombiano de Normas Técnicas y Certificación. (2004). Sistemas de gestión ambiental. Requisitos con orientación para sU USO. NTC 14001. Bogotá, Colombia. ICONTEC.

Ministerio de minas y energía (2015). incidencia real de la minería del carbón, del oro y del uso del mercurio en la calidad ambiental con énfasis especial en el recurso hídrico - diseño de herramientas para la planeación sectorial. Recuperado de: https://wwwl. upme.gov.co/simco/Cifras-Sectoriales/EstudiosPublicaciones/Incidencia_real_de_la_ mineria_sobre_el_recurso_hidrico.pdf\#search=oro

Ministerio del medio ambiente (2018). ABC - Eliminación del mercurio en la minería de oro Ley 1658 del 15 de julio de 2013. Recuperado de : https://www.minambiente.gov. co/images/abc_mercurio.pdf

Muñoz Mesa, L., \& Osorio Beltrán, M. (2018). Caracterización y análisis de las variables locativas, ambientales y de salud ocupacional en joyería. Revista Loginn: Investigación Científica Y Tecnológica, 2(2). https://doi.org/10.23850/25907441.1998

Oficina de las Naciones Unidas contra la Droga y el Delito (UNODC) (2018). Explotación de oro de aluvión. Evidencias a partir de percepción remota 2016. Recuperado de: https://repositoriobi.minminas.gov.co/handle/123456789/2681 
Oficina de las Naciones Unidas contra la Droga y el Delito (UNODC) (2019). Explotación de oro de aluvión. Evidencias a partir de percepción remota 2019. Recuperado de: https://biesimci.org/fileadmin/2020/documentos/evoa/evoa_2019_esp.pdf

Pantoja Timarán, F. H., \& Pantoja Barrios, S. D. (2016). Problemas y desafíos de la minería de oro artesanal y en pequeña escala en Colombia. Revista Facultad De Ciencias Económicas, 24(2), 147-161. https://doi.org/10.18359/rfce.2217

Piragauta, R.A, Montero, Y.C, Rubio, D.M, Sarmiento, S.M, López, C.E (2019). Caracterización de los contaminantes ambientales en los procesos de joyería: diagnóstico de las condiciones de riesgo físico en los ambientes de joyería. Bogotá: Servicio Nacional de Aprendizaje (SENA).

Revista Semana (2015). La Joyería de Colombia: una oportunidad en desarrollo. Bogotá, Colombia. Revista Semana. Recuperado de: https://www.semana.com/ economia/articulo/la-joyeria-colombia-oportunidad-desarrollo/214105/

Rubio, S. (2003). "Investigación de Mercados: Joyería en Antioquia para los Estados Unidos". Colombia. Intermarketing Consultores

Ruiz, J.A., Carmona, M.E., Bolívar, W. y López, C. A. (2017). Valoración de emisiones en los procesos de refinación del oro en joyería y recomendaciones de gestión ambiental. Revista espacios, 38 (46), 12.

Thomas W. Clarkson \& Laszlo Magos (2006) The Toxicology of Mercury and Its Chemical Compounds, Critical Reviews in Toxicology, 36:8, 609-662

Verdad Abierta (6 de Mayo de 2015). Legalizar la minería en el Bajo Cauca: ¿Experimento fallido? Recuperado de: https://verdadabierta.com/legalizacion-dela-mineria-en-bajo-cauca/

Wicks, S (1996) Joyería artesanal, diseño y fabricación artesanal de joyas. Londres, Quill publishing Ltd.

World gold council (30 de abril, 2020). Gold Demand Trends Q1 2020. https://www. gold.org/goldhub/research/gold-demand-trends/gold-demand-trends-q1-2020

\section{Para citar este artículo}

Landazábal, L., Rodríguez, A., Meneses, J., Restrepo, M. (2021). Joyería artesanal en oro. Producción más limpia. Revista Intersección: Eventos, turismo, moda y gastronómia. Vol. 2 Núm. 4. Pp: 20-36; https://doi.org/10.33571/revinterseccion.v2n4a2

OJS: https://revistas.elpoli.edu.co/index.php/int/issue/archive Link: https://www.politecnicojic.edu.co/index.php/revista-interseccion 